\title{
Risk of adverse pregnancy outcome in women exposed to livestock: a study within the Danish National Birth Cohort
}

\author{
S. Y. NIELSEN ${ }^{1,2} *$ T. B. HENRIKSEN ${ }^{1,3}$, N. H. HJØLLUND ${ }^{2,4}$, K. MØLBAK ${ }^{5}$ \\ AND A. M. N. ANDERSEN ${ }^{6}$ \\ ${ }^{1}$ Department of Occupational Medicine, Regional Hospital West Jutland, Herning, Denmark \\ ${ }^{2}$ Perinatal Epidemiology Research Unit, Aarhus University Hospital, Aarhus, Denmark \\ ${ }^{3}$ Department of Paediatrics, Aarhus University Hospital, Aarhus, Denmark \\ ${ }^{4}$ Department of Clinical Epidemiology, Aarhus University Hospital, Aarhus, Denmark \\ ${ }^{5}$ Department of Infectious Disease Epidemiology, Statens Serum Institute, Copenhagen, Denmark \\ ${ }^{6}$ Department of Public Health, University of Copenhagen, Copenhagen, Denmark
}

Received 28 March 2013; Final revision 16 August 2013; Accepted 17 August 2013; first published online 20 September 2013

\section{SUMMARY}

Maternal infection in pregnancy is a known risk factor for adverse pregnancy outcome, and a number of zoonotic pathogens may constitute a risk to pregnant women and their fetuses. With animal contact as a proxy for the risk of zoonotic infection, this study aimed to evaluate pregnancy outcome in women with self-reported occupational or domestic contact with livestock compared to pregnant women without such contact. The Danish National Birth Cohort collected information on pregnancy outcome from 100418 pregnant women (1996-2002) from which three study populations with occupational and/or domestic exposure to livestock and a reference group of women with no animal contact was sampled. Outcome measures were miscarriage, very preterm birth (before gestational week 32), preterm birth (before 37 gestational weeks), small for gestational age (SGA), and perinatal death. Adverse reproductive outcomes were assessed in four different exposure groups of women with occupational or domestic exposure to livestock with no association found between exposure to livestock and miscarriage, preterm birth, SGA or perinatal death. These findings should diminish general occupational health concerns for pregnant women with exposures to a range of different farm animals.

Key words: Miscarriage, pregnancy, preterm birth, zoonoses.

\section{INTRODUCTION}

Maternal infection is a significant risk factor for adverse pregnancy outcomes. It is well established that a number of zoonotic pathogens, including Toxoplasma gondii, Listeria monocytogenes, certain Chlamydia species, and Coxiella burnetii, may

\footnotetext{
* Author for correspondence: Dr S. Y. Nielsen, Department of Clinical Microbiology, Aarhus University Hospital, Brendstrupgaardsvej 100, 8200 Aarhus N, Denmark.

(Email: stineyde@dadlnet.dk)
}

constitute a risk for the pregnant woman and her fetus [1-7]. By contrast, pregnancy outcome following other zoonotic infections including Salmonella, Campylobacter, Yersinia enterocolitica and Brucella is more sparsely described [8-13].

Concerns about women with occupational contact with livestock and thereby a potential risk of exposure to zoonoses has affected guidelines for pregnant women, but knowledge about zoonoses and pregnancy is limited, and as more studies are published, guidelines have been continually adjusted. 
Current Danish guidelines for physicians regarding toxoplasmosis recommend that pregnant women be advised regarding how to prevent exposure to the parasite, whereas neither routine screening nor testing after suspected exposure is recommended. To prevent L. monocytogenes infection, pregnant women are advised to reduce risk by the safe handling as well as avoidance of certain foods [14]. For C. burnetii, screening is recommended for women with relevant exposure to domestic animals, along with precautions regarding the handling of birth products or assisting deliveries [15].

We previously conducted studies of the seroprevalence of $C$. burnetii in Danish women with exposure to livestock, and evaluated pregnancy outcome in seropositive compared to seronegative women within the Danish National Birth Cohort (DNBC). We found a high prevalence of antibodies to C. burnetii in pregnant women with occupational $(47 \cdot 2 \%)$ or domestic $(32.2 \%)$ exposure to cattle or sheep compared to unexposed pregnant women ( $4 \cdot 8 \%$ seropositive), but no increased risk of adverse pregnancy outcome in women with verified exposure to C. burnetii was found [16].

Q fever is endemic in Denmark [17, 18], and our interest in zoonotic pathogens and their possible impact during pregnancy led us to consider pregnancy outcome in women with animal contact in a broader sense. The DNBC is a large, population-based cohort, and with animal contact as a proxy for the risk of zoonotic infection, we sought to evaluate whether selfreported occupational or domestic animal contact was associated with an increased risk of adverse pregnancy outcome.

\section{METHODS}

\section{Participants}

Enrolment in the DNBC took place between 1996 and 2002, and the women were recruited in connection with their first antenatal visit to the general practitioner. The median gestational week of enrolment was 10 weeks (25th and 75 th percentiles: 7 weeks and 13 weeks, respectively), but some women were enrolled as early as gestational week 5 and as late as 22 gestational weeks.

Information on exposures before and during early pregnancy was collected by means of a computerassisted telephone interview scheduled to take place during gestational week 12 or as soon as possible thereafter. If fetal loss occurred before this interview, participants were offered a similar interview as soon as possible after the fetal loss. Questionnaires are available at www.bsmb.dk. Among others, the interviews covered information on reproductive history, smoking status during pregnancy, and domestic contact to animals as well as very detailed information regarding occupational exposure to different animals. A detailed description of the cohort can be found elsewhere [19].

Women representing a total of 92717 pregnancies were interviewed, of which 2552 interviews were carried out after fetal loss. If a woman participated in the cohort with more than one pregnancy, only the first pregnancy was included to avoid nonindependent observations, leading to the exclusion of 8704 interviews. Furthermore, 37 were excluded due to lack of information on gestational age at recruitment. Ectopic pregnancies and pregnancies with mola hydatidosa were also excluded $(n=44)$. For the miscarriage analysis, twin pregnancies $(n=1804)$ were included, but for all other outcomes only singleton pregnancies were included. Thus, 83932 pregnancies were eligible for an analysis of miscarriage and 82128 pregnancies for analysis regarding risk of preterm birth and perinatal death. For analyses on small for gestational age (SGA), 881 were further excluded because of missing or implausible birth-weight data or a gestational age $>44$ weeks, in all 81247 pregnancies.

This study was approved by the Steering Committee for the Danish National Birth Cohort and the Danish Data Protection Agency, and the data collection was, according to Danish legislation, approved by the Regional Research Ethics Committee, and the women enrolled in the DNBC gave written consent for participation.

\section{Exposure measures}

The interviews covered specific questions regarding domestic and occupational exposure to livestock during pregnancy and 3 months prior to pregnancy. Women working on farms were asked: 'Have you worked with farm animal production, that is: with animals?' and 'Which animals do you work with?' Women with other occupational animal exposure than farming were asked: "Which animals do you work with' and 'How are you involved in working with live animals' (veterinarians, veterinary nurses, etc.) and for abattoir workers: 'Are you directly 
involved in handling animals at the abattoir?' Hence, the women could be occupationally exposed to living as well as dead animals.

These questions enabled us to define occupational exposure as women who had worked with livestock either in an abattoir, on a farm, or in veterinary practice. The animals of interest were dairy cattle, meat cattle, pigs, poultry, horses, sheep, and goats.

Similarly, the women who answered 'yes' to living on a farm with livestock (domestic exposure) were asked: 'Which species of animals'? Farm animals were defined as cattle, horses, sheep, pigs, poultry, deer, and goats, with the predominant animals being cattle, sheep, poultry, and pigs. Exposures to pets were not included.

Self-reported information on exposures during pregnancy as well as the 3 months prior to becoming pregnant enabled us to identify four different exposure groups: pregnant women with occupational as well as domestic exposure to livestock $(n=221)$, women with occupational but without domestic exposure $(n=$ 208), women with domestic but without occupational exposure $(n=5248)$, and a reference group of women with no occupational or domestic contact with livestock $(n=76451)$.

Exposure to livestock could be further categorized according to specific animal exposure: cattle $(n=1381)$, sheep $(n=741)$, pigs $(n=871)$ and other $(n=1040)$.

\section{Outcome measures}

Pregnancy outcomes of interest were miscarriage, perinatal death, preterm birth, and SGA. Miscarriage was defined as fetal loss before 154 days (22 weeks) after the first day of the last menstrual period, with gestational age estimated from the participants' selfreported last menstrual period. Perinatal death was defined as fetal death after 22 weeks' gestation or infant death within 7 days of birth.

Preterm birth was categorized into very preterm birth (prior to 32 gestational weeks) and preterm births (before 37 gestational weeks). SGA was estimated by an intrauterine weight standard and defined as a birth weight corresponding to -2 standard deviations and below for the specific gestational age [20]. SGA was also estimated as a birth weight below the lowest 10th percentile for gestational age within the present study population, but the external reference was considered the primary analysis of SGA.
Data on gestational age (days) and birth weight were obtained from the National Patient Registry.

\section{Statistical analysis}

The risk of miscarriage and preterm birth according to animal exposure was estimated as hazard ratios using Cox regression models, with gestational age as the underlying time variable. Using a model for the hazard rate, rather than logistic regression, has a number of advantages. First, gestational age is directly incorporated into the model; second, it makes it possible to take the different gestational durations at entry into the cohort into account.

For miscarriage, time of entry was gestational age at enrolment, and follow-up ended at miscarriage, induced abortion, emigration, or maternal death, or at 22 completed weeks of pregnancy, whatever came first. The analyses of miscarriage were repeated on a subsample restricted to women interviewed while still pregnant (prospective data collection) using gestational age at interview as the time of entry.

For preterm birth follow-up ended at 37 weeks' gestation. Women who emigrated or died prior to this gestational age were censored.

The assumption of proportional hazards was checked by using Schoenfeld residuals. In the group with occupational exposure, there were very few miscarriages $(n=7)$, and the assumption was not fulfilled. Analyses of miscarriages and preterm births were repeated by fitting logistic regression models. The association between exposure to livestock and SGA as well as perinatal death was also estimated by logistic regression models.

Furthermore, all analyses were replicated with restriction to pregnant women who reported employment or who had been unemployed for a maximum period of 6 months prior to becoming pregnant. Analyses restricted to women who were pregnant for the first time and did not have a long time to pregnancy interval ( $<6$ months) were also performed.

Maternal age ( $<25$ years, $25-34$ years, $\geqslant 35$ years), gravidity $(0, \geqslant 1)$, and smoking during pregnancy $(0,1-<10, \geqslant 10$ cigarettes/day) were a priori defined to be included as covariates in all statistical analyses.

\section{RESULTS}

Table 1 shows some characteristics of women according to animal exposure. Of the 82128 women, 
Table 1. Maternal characteristics according to animal exposure (presented for singleton pregnancies) in 82128 women from the Danish National Birth Cohort

\begin{tabular}{|c|c|c|c|c|}
\hline & $\begin{array}{l}\text { Occupational and domestic } \\
\text { exposure to livestock } \\
(n=221)\end{array}$ & $\begin{array}{l}\text { Occupational } \\
\text { exposure to livestock } \\
(n=208)\end{array}$ & $\begin{array}{l}\text { Domestic exposure } \\
\text { to livestock } \\
(n=5248)\end{array}$ & $\begin{array}{l}\text { Unexposed } \\
(n=76451)\end{array}$ \\
\hline \multicolumn{5}{|l|}{ Age (years) } \\
\hline$<25$ & $30(13 \cdot 6)$ & $58(27 \cdot 9)$ & $580(11 \cdot 1)$ & $10387(13 \cdot 6)$ \\
\hline $25-<35$ & $155(70 \cdot 1)$ & $137(65.9)$ & $3847(73 \cdot 3)$ & $57380(75 \cdot 1)$ \\
\hline$\geqslant 35$ & $36(16 \cdot 3)$ & $13(6 \cdot 3)$ & $821(15 \cdot 6)$ & $8684(11 \cdot 4)$ \\
\hline \multicolumn{5}{|l|}{$\begin{array}{l}\text { Gestational age at recruitment } \\
\text { (weeks) }\end{array}$} \\
\hline$<8$ & $20(9)$ & $41(19 \cdot 7)$ & $653(12 \cdot 4)$ & $13762(18)$ \\
\hline $8-11$ & $95(43)$ & $91(43 \cdot 8)$ & $2330(44 \cdot 4)$ & $35604(46 \cdot 6)$ \\
\hline $12-15$ & $75(33 \cdot 9)$ & $54(26)$ & $1532(29 \cdot 2)$ & $19280(25 \cdot 2)$ \\
\hline$\geqslant 16$ & $31(14)$ & $22(10 \cdot 6)$ & $730(13 \cdot 9)$ & $7790(10 \cdot 2)$ \\
\hline \multicolumn{5}{|c|}{ Number of previous pregnancies } \\
\hline 0 & $81(36 \cdot 7)$ & $97(46 \cdot 6)$ & $1515(28 \cdot 9)$ & $29569(38 \cdot 7)$ \\
\hline$\geqslant 1$ & $140(63 \cdot 4)$ & $111(53 \cdot 4)$ & $3730(71 \cdot 1)$ & $46849(61 \cdot 3)$ \\
\hline Missing & 0 & 0 & $3(0 \cdot 06)$ & $33(0 \cdot 04)$ \\
\hline \multicolumn{5}{|l|}{ Smoking } \\
\hline Non-smokers & $201(91)$ & $169(81 \cdot 3)$ & $4457(84 \cdot 9)$ & $64222(84)$ \\
\hline $1-<10$ cigarettes/day & $8(3 \cdot 6)$ & $18(8 \cdot 7)$ & $381(7 \cdot 3)$ & $6173(8 \cdot 1)$ \\
\hline$\geqslant 10$ cigarettes/day & $12(5 \cdot 4)$ & $21(10 \cdot 1)$ & $408(7 \cdot 8)$ & $6016(7 \cdot 9)$ \\
\hline Missing & 0 & 0 & $2(0 \cdot 04)$ & $40(0 \cdot 05)$ \\
\hline \multicolumn{5}{|l|}{ Social status } \\
\hline Higher grade professionals & $32(14 \cdot 5)$ & $65(31 \cdot 25)$ & $758(14 \cdot 4)$ & $18265(23.9)$ \\
\hline Lower grade professionals & $43(19 \cdot 5)$ & $29(13 \cdot 9)$ & $1696(32 \cdot 2)$ & $23551(30 \cdot 8)$ \\
\hline Skilled workers & $139(62 \cdot 9)$ & $81(38 \cdot 9)$ & $2062(39 \cdot 3)$ & $20807(27 \cdot 2)$ \\
\hline Unskilled workers & $5(2 \cdot 3)$ & $27(12 \cdot 9)$ & $652(12 \cdot 4)$ & $11092(14 \cdot 5)$ \\
\hline Students & $2(0 \cdot 9)$ & $5(2 \cdot 4)$ & $37(0 \cdot 7)$ & $1976(2 \cdot 6)$ \\
\hline Economically inactive & 0 & 0 & $32(0 \cdot 6)$ & $590(0 \cdot 8)$ \\
\hline Unclassified & 0 & $1(0 \cdot 5)$ & $11(0 \cdot 2)$ & $170(0 \cdot 2)$ \\
\hline \multicolumn{5}{|l|}{ Employment status } \\
\hline Working* & $220(99 \cdot 6)$ & 206 (99) & $4383(83 \cdot 5)$ & $64641(84 \cdot 6)$ \\
\hline Out of work $\dagger$ & $1(0 \cdot 5)$ & $2(1)$ & $865(16 \cdot 5)$ & $11810(15 \cdot 4)$ \\
\hline
\end{tabular}

Values given are $n(\%)$.

* Or out of work for a maximum of up to 6 months prior to becoming pregnant.

$\dagger$ For $>6$ months prior to pregnancy.

$5830(6.9 \%)$ reported occupational or domestic contact with livestock in their pregnancy or 3 months prior to becoming pregnant.

Women with occupational or domestic contact with livestock were recruited at a higher gestational age, were younger, of higher parity, and were more often smokers than women without such contact.

Table 2 presents hazard ratios for miscarriage and preterm birth in women with various animal contacts compared to unexposed women. A total of 2846 $(3.4 \%)$ pregnancies resulted in miscarriages, and the median gestational age at miscarriage was 12 weeks 6 days [interquartile range (IQR) 10-14 weeks] for women with occupational and domestic contact with livestock, compared to 11 weeks 6 days (IQR 10-13 weeks) in unexposed women.

Neither occupational nor domestic exposure was found to be associated with miscarriage.

The majority of fetal losses occurred early in pregnancy, and consequently, interview data were obtained after miscarriage for a considerable number of miscarriages in the cohort. However, in the analysis restricted to women who were interviewed while still pregnant, the estimates obtained were essentially the same (results not shown).

For the occupationally exposed group as well as the group with occupational as well as domestic exposure, there were too few events to perform adjusted 
Table 2. Hazard ratios (HR) of miscarriage, preterm birth and perinatal death according to animal exposure during pregnancy or 3 months prior to becoming pregnant, with unexposed women as reference group, for 83932 women (miscarriage) and 82128 women (preterm birth and perinatal death) from the Danish National Birth Cohort

\begin{tabular}{|c|c|c|c|c|c|c|c|c|c|c|c|c|}
\hline & \multicolumn{4}{|c|}{ Miscarriage (<22 weeks) } & \multicolumn{4}{|c|}{ Very preterm birth $(22-31+6$ weeks $)$} & \multirow{2}{*}{\multicolumn{4}{|c|}{ Preterm birth (22-36+6 weeks) }} \\
\hline & & & & & & & & & & & & \\
\hline & $\begin{array}{l}\text { Miscarriage } \\
n(\%)\end{array}$ & $\begin{array}{l}\text { miscarriage } \\
n(\%)\end{array}$ & $\begin{array}{l}\text { Crude } \\
\text { HR }\end{array}$ & $\begin{array}{l}\text { aHR* } \\
(95 \% \mathrm{CI})\end{array}$ & $\begin{array}{l}\text { preterm birth } \\
n(\%)\end{array}$ & $n(\%)$ & HR & $\begin{array}{l}\text { aHR* } \\
(95 \% \mathrm{CI})\end{array}$ & $\begin{array}{l}\text { Preterm } \\
n(\%)\end{array}$ & $\begin{array}{l}\text { Not preterm } \\
n(\%)\end{array}$ & HR & $\begin{array}{l}\text { aHR* } \\
(95 \% \mathrm{CI})\end{array}$ \\
\hline $\begin{array}{l}\text { No livestock } \\
\text { exposure }\end{array}$ & $2666(3 \cdot 4)$ & $75436(96 \cdot 6)$ & 1 (ref.) & & $674(0 \cdot 9)$ & $72902(99 \cdot 1)$ & 1 (ref.) & & $3689(5 \cdot 0)$ & $69887(95)$ & 1 (ref.) & \\
\hline $\begin{array}{l}\text { Domestic exposure } \\
\text { to livestock }\end{array}$ & $162(3)$ & $5235(97)$ & $0 \cdot 9$ & $0 \cdot 9(0 \cdot 8-1 \cdot 1)$ & $30(0 \cdot 6)$ & $5077(99 \cdot 4)$ & $0 \cdot 65$ & $0 \cdot 66(0 \cdot 5-1 \cdot 0)$ & $232(4 \cdot 6)$ & $4845(95 \cdot 4)$ & $0 \cdot 9$ & $0 \cdot 9(0 \cdot 8-1 \cdot 1)$ \\
\hline $\begin{array}{l}\text { Occupational } \\
\text { exposure } \\
\text { to livestock }\end{array}$ & $7(3 \cdot 4)$ & $202(96 \cdot 7)$ & $1 \cdot 0$ & n.a. $\dagger$ & $1(0 \cdot 5)$ & $200(99 \cdot 5)$ & n.a.t & n.a.t & $8(4 \cdot 0)$ & $193(96 \cdot 0)$ & $0 \cdot 8$ & n.a. $\dagger$ \\
\hline $\begin{array}{l}\text { Occupational and } \\
\text { domestic exposure } \\
\text { to livestock }\end{array}$ & $11(4 \cdot 9)$ & $213(95 \cdot 1)$ & $1 \cdot 6$ & n.a. $\dagger$ & $1(0 \cdot 5)$ & $210(99 \cdot 5)$ & n.a.t & n.a.t & $7(3 \cdot 3)$ & $203(96 \cdot 7)$ & $0 \cdot 7$ & n.a. $\dagger$ \\
\hline
\end{tabular}

aHR, Adjusted hazard ratio; CI, confidence interval.

* Adjusted for maternal age, gravidity and smoking.

$\dagger$ Not available due to too few events, but in logistic regression analysis the crude estimates were identical, and adjustment for maternal age, gravidity and smoking did not change the estimates.

$\$$ Not available due to too few events. 
Table 3. Small for gestational age ( $S G A$ ) parameters for Danish pregnant women according to animal exposure

\begin{tabular}{|c|c|c|c|c|c|c|c|c|}
\hline & \multicolumn{4}{|c|}{$\begin{array}{l}\text { SGA [gestational week } 22 \text { and onwards } \\
\text { (external reference)] }\end{array}$} & \multicolumn{4}{|c|}{$\begin{array}{l}\text { Perinatal death (gestational week } \\
22-7 \text { days post-term) }\end{array}$} \\
\hline & $\begin{array}{l}\text { SGA } \\
n(\%)\end{array}$ & $\begin{array}{l}\text { Not SGA } \\
n(\%)\end{array}$ & $\begin{array}{l}\text { Crude } \\
\text { OR }\end{array}$ & $\begin{array}{l}\text { adjusted } \\
\text { OR* } \\
(95 \% \mathrm{CI})\end{array}$ & $\begin{array}{l}\text { Perinatal } \\
\text { death } \\
n(\%)\end{array}$ & $\begin{array}{l}\text { No perinatal } \\
\text { death } \\
n(\%)\end{array}$ & $\begin{array}{l}\text { OR } \\
\text { crude }\end{array}$ & $\begin{array}{l}\text { adjusted } \\
\text { OR* } \\
(95 \% \mathrm{CI})\end{array}$ \\
\hline No animal exposure & $2080(2 \cdot 9)$ & $70648(97 \cdot 1)$ & 1 (ref.) & & $536(0 \cdot 7)$ & $73040(99 \cdot 3)$ & 1 (ref.) & \\
\hline $\begin{array}{l}\text { Domestic exposure } \\
\text { to livestock }\end{array}$ & $111(2 \cdot 2)$ & $4934(97 \cdot 8)$ & $0 \cdot 8$ & $0 \cdot 8(0 \cdot 7-1 \cdot 0)$ & $30(0 \cdot 6)$ & $5047(99 \cdot 4)$ & $0 \cdot 8$ & $0 \cdot 8(0 \cdot 6-1 \cdot 0)$ \\
\hline $\begin{array}{l}\text { Occupational } \\
\text { exposure } \\
\text { to livestock }\end{array}$ & $6(3)$ & $195(97 \cdot 0)$ & $1 \cdot 1$ & $1 \cdot 0(0 \cdot 5-2 \cdot 2)$ & $2(1)$ & $199(99 \cdot 0)$ & $1 \cdot 3$ & $1 \cdot 4(0 \cdot 4-5 \cdot 6)$ \\
\hline $\begin{array}{l}\text { Occupational } \\
\text { and domestic } \\
\text { exposure to livestock }\end{array}$ & $5(2 \cdot 4)$ & $204(97 \cdot 6)$ & $0 \cdot 8$ & n.a. $\dagger$ & $2(1)$ & $208(99 \cdot 0)$ & $1 \cdot 3$ & $1 \cdot 3(0 \cdot 3-5 \cdot 3)$ \\
\hline
\end{tabular}

OR, Odds ratio; CI, confidence interval.

* Adjusted for smoking, gravidity and maternal age.

$\dagger$ Not available due to too few events.

hazard ratios. For these groups, miscarriage analyses were repeated using logistic regression which did not change the estimates (results not shown).

Of a total of 3936 preterm deliveries, 247 reported animal contact. No increased risk of very preterm or preterm birth was found for any kind of animal exposure (Table 2). Here there were also too few events to perform adjusted hazard ratios for the occupationally exposed group as well as the group with occupational and domestic exposure. For these groups, preterm birth analyses were repeated using logistic regression, which did not change the estimates (results not shown).

In all, 2202 women were SGA, and we found no association between contact with livestock and SGA (Table 3) except for the group with domestic contact [odds ratio (OR) $0 \cdot 8,95 \%$ confidence interval (CI) $0 \cdot 6-1 \cdot 0, P=0 \cdot 03]$. However, in analyses repeated on term births only, no association was found (results not shown).

No association between any exposure to livestock and perinatal death $(n=570)$ was found (Table 3$)$.

In the group with domestic exposure to livestock, stratified analyses by different types of animal contact: sheep $(n=741)$, cattle $(n=1381)$, pigs $(n=871)$, poultry $(n=1040)$, and other $(n=1364)$ were performed.

No significant association was found between contact with any of the specific animal types and miscarriage, preterm birth, or perinatal death. However, exposure to pigs was associated with a decreased risk of SGA (OR $0 \cdot 5,95 \%$ CI $0 \cdot 3-0 \cdot 9$ ). But in analysis restricted to term births, the protective effect was absent.

Analyses restricted to women who reported being employed or having been unemployed for a maximum period of 6 months prior to becoming pregnant did not change any outcome measures significantly (results not shown). Nor did analyses restricted to women who were pregnant for the first time and did not have a long time to pregnancy interval (<6 months) (results not shown).

\section{DISCUSSION}

Overall, we found no association between exposure to Danish livestock and adverse pregnancy outcome. Analyses in separate categories for occupational and domestic exposure as well as restricting analysis to women in the labour market failed to change this. Nor did analyses stratified with regard to specific animals.

To our knowledge, this is the first population-based study to address pregnancy outcome in women with self-reported contact with livestock evaluated in separate groups of domestic and occupational exposure, as well as in a group with both exposures.

We assumed that exposure to livestock during pregnancy or during a period of 3 months prior to becoming pregnant could be a proxy for exposure to zoonotic pathogens and hypothesized that animal contact would be associated with an increased risk 
of adverse pregnancy outcome. Our hypothesis was not confirmed.

At the time of the study (1996-2002), zoonotic pathogens were common in Danish livestock. For example, in 1998, the prevalence of Salmonella was $6.5 \%$ in Danish broiler chickens and 3.7\% in pigs, whereas the prevalence of Campylobacter was as high as $47 \cdot 1 \%$ in broilers and $68 \cdot 8 \%$ in pigs [21].

Between 1994 and 2005, 37 confirmed cases of maternal-fetal L. monocytogenes infections were reported in Denmark [22], and a study from 1995 found that $27 \cdot 4 \%$ of 5402 Danish pregnant women had IgG antibodies against $T$. gondii $[2,23]$.

More recent Danish studies on the prevalence of zoonotic pathogens have found that Campylobacter is the most frequently reported foodborne pathogen in Denmark. In 2011, the registered number of Campylobacter cases was 4068 (73.1 cases $/ 100000$ inhabitants) compared to 1166 Salmonella cases ( 21.0 cases/ 100000 inhabitants); it was 224 for Yersinia and 49 for Listeria [24]. Moreover, analysis showed a clonal link between Escherichia coli from humans and broiler chickens, broiler chicken meat, pork and pigs, suggesting that production animals may pose a zoonotic risk [25, 26].

Foodborne outbreaks of $L$. monocytogenes have been described, and since 2002 the incidence of Listeria has increased in Denmark as well as in several other European countries [3, 27, 28]; in 2009, 97 cases were reported in Denmark, compared to 57 in 2008. Fifty of these cases were in females and three were maternal-fetal infections [29].

We find it reasonable to assume that most of the women with domestic or occupational contact with livestock are exposed to zoonotic pathogens, primarily Campylobacter and Salmonella, but also to ubiquitous agents such as Toxoplasma and Listeria $[2,28,29]$. In pig farmers and veterinarians, exposure to $Y$. enterocolitica is likely, and individuals working with cattle, sheep, or goats would have a risk of verocytotoxin-producing $E$. coli or $C$. burnetii exposure $[17,18,30]$.

In our main analyses, we did not differentiate between types of animals because the aim was to address occupational and domestic exposure, rather than to address a possible risk of exposure from specified animals. In order to further analyse occupational exposure, we performed analyses restricted to women who were working during or 2 months prior to pregnancy, but this did not affect any outcome measures significantly.
As indicated above, some zoonotic infections are restricted to specific animal species, whereas others are widespread, which is the justification for studying individual species. Analyses stratified by type of animal failed to reveal any risk of adverse pregnancy outcome according to specific animal contact.

It is possible that pregnant women, once they know about their pregnancy, modify their behaviour in order to limit contact with livestock and pay increased attention to, for instance, hand hygiene. This may especially be an issue in women with a history of adverse pregnancy outcomes. This change may modify the potential risks from zoonotic infections. There are, however, limited data to quantify the health impact of this possible change in behaviour [31].

Moreover, we do not have data on the women's exposure before their pregnancy addressing a possible recent change in occupational or domestic exposure; hence, we do not know if the risk is different for women with a recent change in exposure status, as the role of immunity will be different in these groups.

This is a very large study. Despite this, some analyses suffered from very low power due to the relatively low proportion of exposed women and to the infrequency of the study's outcomes, resulting in few events in some of the analyses. Also, due to the gestational age at enrolment into the cohort, the earliest miscarriages were not included. Consequently, we were unable to reveal a potential harmful effect in the pre-clinical phase of pregnancy.

If women with a history of adverse pregnancy outcome have a tendency to avoid animal exposure, this could introduce behaviour modification bias. However, since analyses restricted to women who were pregnant for the first time and did not have a long time to pregnancy interval $(<6$ months) did not change any estimates significantly; this was not an issue in this cohort.

We chose to adjust all events for three important risk factors for adverse reproductive outcome.

Age is an important factor determining miscarriage risk, and smoking is a well-known risk factor for preterm birth. Adjustment for smoking in the analyses of miscarriages was justified by the inconsistency of previous findings related to smoking and miscarriage [32]. Other confounding factors could be socioeconomic status or strenuous leisure time physical exercise [33]. If socioeconomic status was an essential risk factor for any of the outcomes included in this cohort, it would result in different estimates in sub-analyses in women with a connection with 
the workforce. For women living and/or working on farms, with physical activity incorporated into daily routines, a possible effect of leisure time exercise is difficult to quantify.

There could be characteristics entailing different behaviours in women living and/or working on farms that could alter their pregnancy outcome, for instance heavy physical work and perhaps less focus on a healthy lifestyle in pregnancy compared to women living in cities. But since our findings are negative, these aspects are probably of minor importance, but would have been taken into account had we found an association between animal contact and adverse pregnancy outcome.

On the other hand, women living in the countryside are less prone to exposure to outdoor air pollution from traffic, which is associated with low birth weight and preterm birth [34]; this could lead to confounding, but is speculative.

A number of women with miscarriage in this study were interviewed after their miscarriage, and recall bias must be taken into account since they may report exposures differently than women who are interviewed while still pregnant, which is why analyses restricted to women interviewed prior to pregnancy outcome were also performed.

Livestock management practices may change. However, the interplay of causal factors of zoonotic infections in a complex pathway is not new, illustrated for example, by the recent unprecedented epidemic of Q fever in The Netherlands [35]. With the increasing availability of modern diagnostics and rigorous screening, a higher proportion of test results indicating past or present infections may be detected during pregnancy. Larger seroepidemiological studies on the various zoonoses are needed to further clarify their hazard to human fetal health.

For several infections suspected of or known to constitute a potential hazard to a healthy pregnancy outcome, exposures in professional vs. private life are difficult to separate.

For toxoplasmosis, for instance, clinical Danish guidelines for pregnant women have changed in recent years [14]. This is due to the latest research, which does not provide evidence that prenatal treatmentfrom screening in pregnancy-reduces the risk of mother-to-child transmission of Toxoplasma infection, but also to the fact that detaching occupational from non-occupational exposures is very difficult; attempts to avoid occupational exposure for veterinarians, for instance, have been deemed of no use.
Adverse reproductive outcomes were assessed in four different exposure groups of women with occupational or domestic exposure to livestock. The fact that this large study found no association between exposure to livestock and miscarriage, preterm birth, SGA or perinatal death should diminish general occupational health concerns for pregnant women with general exposures to a range of different farm animals.

\section{DECLARATION OF INTEREST}

None.

\section{ACKNOWLEDGEMENTS}

This work was supported by Danish Working Environment Research Fund (S.Y.N.), and the Danish Ramazzinicenter (S.Y.N.)

\section{REFERENCES}

1. Lappalainen M, et al. Outcome of children after maternal primary Toxoplasma infection during pregnancy with emphasis on avidity of specific IgG. The Study Group. Pediatric Infectious Disease Journal 1995; 14: 354-361.

2. Lebech M, Larsen SO, Petersen E. Occurrence of toxoplasmosis in pregnant women in Denmark. A study of 5.402 pregnant women. Ugeskrift for laeger 1995; 157: 5242-5245.

3. Smith B, et al. Listeria monocytogenes: maternal-foetal infections in Denmark 1994-2005. Scandinavian Journal of Infectious Diseases 2009; 41: 21-25.

4. Raoult D, Fenollar F, Stein A. Q fever during pregnancy: diagnosis, treatment, and follow-up. Archives of Internal Medicine 2002; 162: 701-704.

5. Carcopino X, et al. Q Fever during pregnancy: a cause of poor fetal and maternal outcome. Annals of the New York Academy of Sciences 2009; 1166: 79-89.

6. Carcopino X, et al. Managing Q fever during pregnancy: the benefits of long-term cotrimoxazole therapy. Clinical Infectious Diseases 2007; 45: 548-555.

7. Baud D, Regan L, Greub G. Emerging role of Chlamydia and Chlamydia-like organisms in adverse pregnancy outcomes. Current Opinion in Infectious Diseases 2008; 21: 70-76.

8. Elshamy M, Ahmed AI. The effects of maternal brucellosis on pregnancy outcome. Journal of Infection in Developing Countries 2008; 2: 230-234.

9. Kurdoglu M, et al. Brucellosis in pregnancy: a 6-year clinical analysis. Archives of Gynecology and Obstetrics 2010; 281: 201-206.

10. Coughlin LB, et al. Salmonella sepsis and miscarriage. Clinical Microbiology and Infection 2003; 9: 866-868.

11. van der Klooster JM, Roelofs HJ. Management of Salmonella infections during pregnancy and puerperium. The Netherlands Journal of Medicine 1997; 51: 83-86. 
12. Sauerwein RW, Bisseling J, Horrevorts AM. Septic abortion associated with Campylobacter fetus subspecies fetus infection: case report and review of the literature. Infection 1993; 21: 331-333.

13. Steinkraus GE, Wright BD. Septic abortion with intact fetal membranes caused by Campylobacter fetus subsp. fetus. Journal of Clinical Microbiology 1994; 32: 1608-1609.

14. Danish National Board of Health. Recommendations for pregnancy care (http://www.sst.dk/publ/publ2009/CFF/ gravide/svangreomsorgen.pdf).

15. Nielsen SY. Q fever-guidelines for occupational medicine (http://armoni.dk/sites/default/files/Armoni_ Fildeling/files/Public/Q_feber1.pdf). Accessed December 2012.

16. Nielsen SY, et al. No excess risk of adverse pregnancy outcomes among women with serological markers of previous infection with Coxiella burnetii: evidence from the Danish national birth cohort. BMC Infectious Diseases 2013; 13: 87.

17. Bacci S, et al. Epidemiology and clinical features of human infection with Coxiella burnetii in Denmark During 2006-07. Zoonoses and Public Health 2011; 59: 61-68.

18. Bosnjak E, et al. Emerging evidence for $\mathrm{Q}$ fever in humans in Denmark: role of contact with dairy cattle. Clinical Microbiology and Infection 2010; 16: 12851288.

19. Olsen J, et al. The Danish National Birth Cohort - its background, structure and aim. Scandinavian Journal of Public Health 2001; 29: 300-307.

20. Marsal K. Intrauterine growth restriction. Current Opinion in Obstetrics \& Gynecology 2002; 14: 127-135.

21. Annual Report on zoonoses in Denmark, 1998 (http:// www.food.dtu.dk/english/ /media/institutter/foedevare instituttet/publikationer/pub-1999/annrepzoonoses 98. ashx). Accessed December 2012.

22. Smith B, et al. Listeria monocytogenes: maternal-foetal infections in Denmark 1994-2005. Scandinavian Journal of Infectious Diseases 2009; 41: 21-25.

23. Lebech M, et al. Feasibility of neonatal screening for toxoplasma infection in the absence of prenatal treatment. Danish Congenital Toxoplasmosis Study Group. Lancet 1999; 353: 1834-1837.
24. Annual report on zoonosis, 2011 (http://www.food.dtu. $\mathrm{dk} / \sim /$ media/institutter/foedevareinstituttet/publikationer/ pub-2012/annual $\% 20$ report $\% 20$ on $\% 20$ zoonoses $\% 20 \mathrm{in} \%$ 20denmark\%202011.ashx). Accessed December 2012.

25. Jakobsen $\mathbf{L}$, et al. Is Escherichia coli urinary tract infection a zoonosis? Proof of direct link with production animals and meat. European Journal of Clinical Microbiology and Infectious Diseases 2012; 31: 1121-1129.

26. Jakobsen L, et al. Broiler chickens, broiler chicken meat, pigs and pork as sources of ExPEC related virulence genes and resistance in Escherichia coli isolates from community-dwelling humans and UTI patients. International Journal of Food Microbiology 2010; 142: 264-272.

27. Smith B, et al. Outbreak of listeriosis caused by infected beef meat from a meals-on-wheels delivery in Denmark 2009. Clinical Microbiology and Infection 2011; 17: 5052.

28. Goulet $\mathbf{V}$, et al. Increasing incidence of listeriosis in France and other European countries. Emerging Infectious Diseases 2008; 14: 734-740.

29. Kvistholm Jensen A, et al. Substantial increase in listeriosis, Denmark 2009. Eurosurveillance 2010; 15: 19522.

30. Breum SO, Boel J. Prevalence of Escherichia coli O157 and verocytotoxin producing E. coli (VTEC) on Danish beef carcasses. International Journal of Food Microbiology 2010; 141: 90-96.

31. Edvardsson K, et al. Giving offspring a healthy start: parents' experiences of health promotion and lifestyle change during pregnancy and early parenthood. $B M C$ Public Health 2011; 11: 936.

32. Wilcox AJ. Fertility and Pregnancy: an Epidemiologic Perspective. New York, NY: Oxford University Press, 2010, pp. xii, 324.

33. Madsen M, et al. Leisure time physical exercise during pregnancy and the risk of miscarriage: a study within the Danish National Birth Cohort. British Journal of Obstetrics and Gynaecology 2007; 114: 1419-1426.

34. Stieb DM, et al. Ambient air pollution, birth weight and preterm birth: a systematic review and meta-analysis. Environmental Research 2012; 117: 100-111.

35. van der Hoek W, et al. Q fever in the Netherlands: an update on the epidemiology and control measures. Eurosurveillance 2010; 15: 19520. 